\title{
Intraductal papillary mucinous neoplasm of the Santorini duct in a patient with pancreas divisum diagnosed by transpapillary biopsy
}
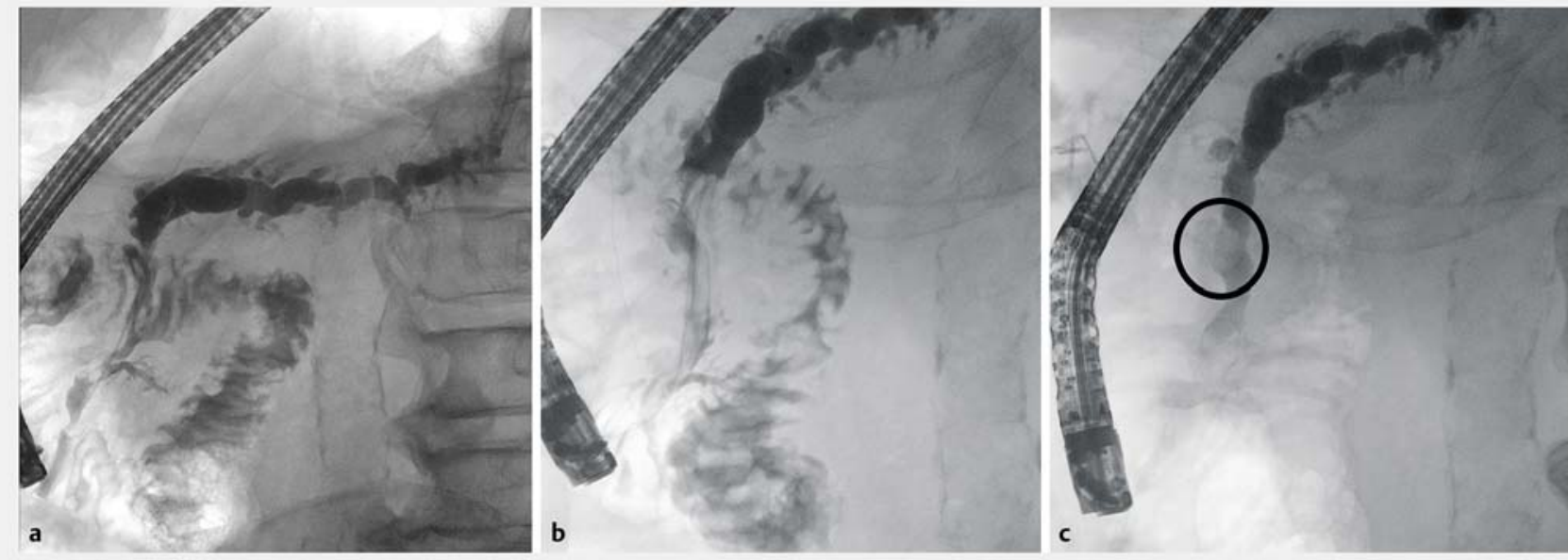

Fig. 1 Pancreatogram images showing: a the initial appearance of the narrow Santorini duct; $\mathbf{b}$ the broad and shallow contrast passage in the Santorini duct owing to the presence of mucus; $\mathbf{c}$ a tumorous lesion in the Santorini duct.

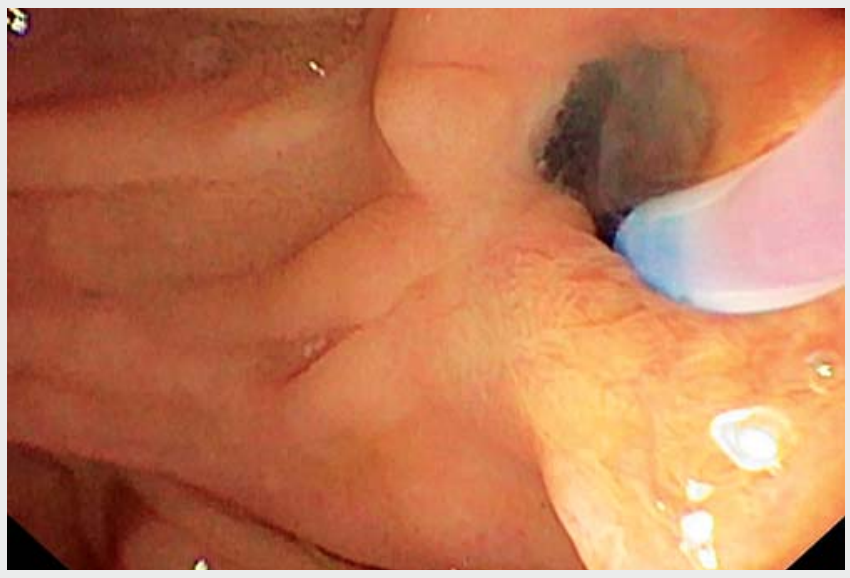

$\checkmark$ Video 1 Intraductal papillary mucinous neoplasm of the Santorini duct in a patient with pancreas divisum diagnosed by transpapillary biopsy.

A 76-year-old patient presented with pancreatic duct dilatation on magnetic resonance imaging (MRI). The patient had no symptoms and no previous history of hepatobiliary or pancreatic disease. Endosonography showed pancreatic duct dilatation $(12 \mathrm{~mm})$ in the pancreatic body and tail. The pancreatic duct in the pancreatic head was only moderately dilated ( $5 \mathrm{~mm})$.

Endoscopic retrograde cholangiopancreatography (ERCP) showed a normal major papilla and normal biliary system. Pancreatography revealed a blind-ending main pancreatic duct of only $35 \mathrm{~mm}$ in length. The minor papilla was found in

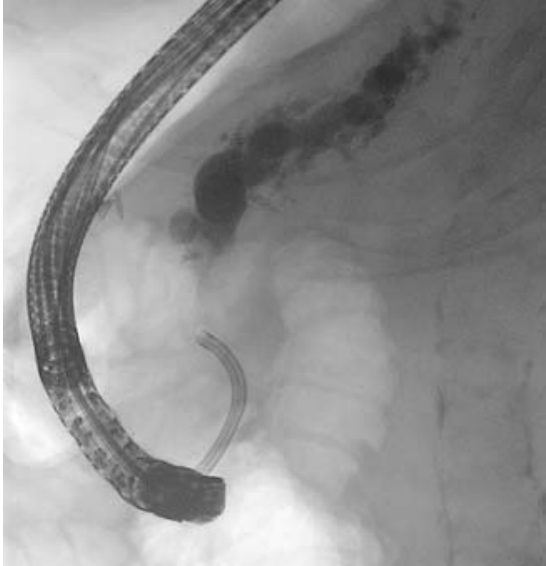

Fig. 2 Direct pancreatoscopy is performed using the SpyGlass DS System (Boston Scientific Corporation, Marlborough, Massachusetts, USA).

the typical position, $2 \mathrm{~cm}$ above the major papilla. Pancreatography confirmed the dilated main pancreatic duct in the pancreatic body and tail, with a narrow Santorini duct ( $\triangleright$ Fig. 1 a), so a plastic drain was inserted. Chronic pancreatitis because of pancreas divisum was assumed to be the reason for the duct dilatation. 
During follow-up ERCP 10 weeks later, pancreatography showed the typical sign of mucus in the Santorini duct, with shallow contrast passage ( Fig.1 b). After the extraction of a large amount of mucus, a mucinous tumor measuring $14 \mathrm{~mm}$ was detected in the Santorini duct ( Fig. 1 c). Transpapillary biopsy was performed using a one-sided opening-cup biopsy forceps (Olympus Corporation, Tokyo, Japan) and pathological results showed an intrapapillary mucinous neoplasm (IPMN). Because of the location of the neoplasm within the Santorini duct in a pancreas divisum, this was classified as a main duct IPMN ( $\triangleright$ Video 1 ).

In line with the revised Fukuoka guidelines [1], surgery was considered; however, after discussion with the patient, surgery was not pursued owing to the patient's cardiological co-morbidities. Further surveillance was performed by direct pancreatoscopy (SpyGlass DS System, Boston Scientific Corporation, Marlborough, Massachusetts, USA) and the typical papillary structure of an IPMN was seen, with re-biopsy performed ( Fig. 2).

IPMN of the Santorini duct is a rare finding [2]. This case outlines the difficulty of differentiating between chronic pancreatitis and carcinoma of the pancreas and its precursor lesions.

Endoscopy_UCTN_Code_CCL_1AZ_2AB
Competing interests

The authors declare that they have no conflict of interest.

\section{The authors}

Franz Singhartinger ${ }^{1} \stackrel{\oplus}{\text { Martin Varga }}{ }^{1}$, Antonia Gantschnigg ${ }^{1}{ }^{\oplus}$, Andrej Wagner ${ }^{2}$, Oliver Koch', Klaus Emmanuel' , Josef Holzinger ${ }^{1}$

1 Department of Surgery, Paracelsus Medical University/Salzburger Landeskliniken (SALK), Salzburg, Austria

2 Department of Internal Medicine I, Paracelsus Medical University/Salzburger Landeskliniken (SALK), Salzburg, Austria

\section{Corresponding author}

\section{Franz Singhartinger, MD}

Paracelsus Medical University, Salzburger Landeskliniken (SALK), Müllner Hauptstraße 48, 5020 Salzburg, Austria f.singhartinger@salk.at

\section{References}

[1] Tanaka M, Fernández-Del Castillo C, Kamisawa T et al. Revisions of international consensus Fukuoka guidelines for the management of IPMN of the pancreas. Pancreatology $2017 ; 17: 738-753$

[2] Shia J, Agaram NP, Olgac $S$ et al. Adenocarcinoma of the minor duodenal papilla and its precursor lesions: a clinical and pathologic study. Am J Surg Pathol 2014; 38: 526-533
Bibliography

Endoscopy 2022; 54: E615-E616

DOI 10.1055/a-1722-2539

ISSN 0013-726X

published online 26.1.2022

(c) 2022. Thieme. All rights reserved.

Georg Thieme Verlag KG, Rüdigerstraße 14,

70469 Stuttgart, Germany

\section{ENDOSCOPY E-VIDEOS}

https://eref.thieme.de/e-videos

口南回 Endoscopy E-Videos is an

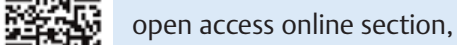
回躲: reporting on interesting cases and new techniques in gastroenterological endoscopy. All papers include a high quality video and all contributions are freely accessible online. Processing charges apply (currently EUR 375), discounts and wavers acc. to HINARI are available.

This section has its own submission website at https://mc.manuscriptcentral.com/e-videos 